\title{
Foraging efficiency, social status and body condition in group- living horses and ponies
}

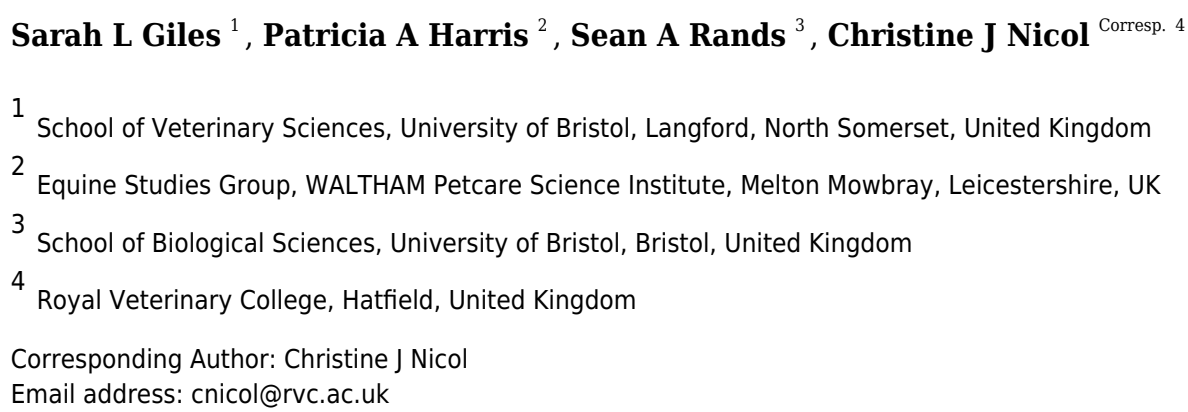

Individual animals experience different costs and benefits associated with group living, which may impact on their foraging efficiency in ways not yet well specified. This study investigated associations between social dominance, body condition and interruptions to foraging behaviour in a cross-sectional study of 116 domestic horses and ponies, kept in 20 discrete herds. Social dominance was measured for each individual alongside observations of winter foraging behaviour. During bouts of foraging, the duration, frequency and category (vigilance, movement, social displacements given and received, scratching and startle responses) of interruptions were recorded, with total interruption time taken as a proxy measure of foraging efficiency. Total foraging time was not influenced by body condition or social dominance. Body condition was associated with social dominance, but more strongly associated with foraging efficiency. Specifically, lower body condition was associated with greater vigilance. This demonstrates that factors other than social dominance can result in stable differences in winter body condition. 


\section{Foraging efficiency, social status and body condition 2 in group-living horses and ponies.}

3

4 Sarah.L.Giles ${ }^{1}$, Patricia.A.Harris ${ }^{2}$, Sean.A.Rands ${ }^{3}$ and Christine.J. Nicol ${ }^{4 *}$

5 1. School of Veterinary Science, University of Bristol, Langford, Bristol UK.

6 2. Equine Studies Group, WALTHAM Petcare Science Institute, Melton Mowbray,

7 Leicestershire UK.

8 3. School of Biological Sciences, University of Bristol, Bristol UK.

9 4. Royal Veterinary College, Hatfield, UK

$10 *$ Corresponding Author:

11 Christine Nicol,

12 Royal Veterinary College, Hawkshead Lane, Brookmans Park, Hatfield, AL9 7TA

13 Email address: cnicol@rvc.ac.uk

\section{Abstract}

Individual animals experience different costs and benefits associated with group living, which may impact on their foraging efficiency in ways not yet well specified. This study investigated associations between social dominance, body condition and interruptions to foraging behaviour in a cross-sectional study of 116 domestic horses and ponies, kept in 20 discrete herds. Social dominance was measured for each individual alongside observations of winter foraging behaviour. During bouts of foraging, the duration, frequency and category (vigilance, movement, social displacements given and received, scratching and startle responses) of interruptions were recorded, with total interruption time taken as a proxy measure of foraging efficiency. Total foraging time was not influenced by body condition or social dominance. Body condition was associated with social dominance, but more strongly associated with foraging efficiency. Specifically, lower body condition was associated with greater vigilance. This demonstrates that factors other than social dominance can result in stable differences in winter body condition. 


\section{Introduction}

32 Social behaviour can influence energetic reserves and subsequent body condition. Previous modelling studies have outlined the potential importance of social effects on foraging behaviour (bouts of biting, chewing and swallowing interrupted by relocation movements) in determining body condition in group living animals (Houston and McNamara, 1999; Rands et al., 2003; 2004; 2006; 2008) and also the role of dominance behaviours in determining resource access and subsequent body condition (Clark and Ekman, 1995; Stillman et al., 1997; Rands et al., 2006). Thus, the foraging success of individual animals in social groups may be partly influenced by their social status. However, few of these predictions have been investigated empirically in socially-foraging herbivores and the relationship between herd behaviours, dominance and body condition is not fully understood.

In a socially foraging herbivore the benefits of group living outweigh the costs (Krause and Ruxton, 2002). Individual animals living within groups follow behavioural rules which allow them to function as a social unit (Hemelrijk, 2002; Rands, 2011a,b). These rules are likely to depend upon both aspects of their own body condition (such as energetic reserves) and also the actions of other individuals within the group (Houston and McNamara, 1999; Rands et al., 2003; 2008). Rules governing social interaction (e.g. dominance) may be important for a wellfunctioning group in terms of minimising costly conflict over resources (Krause and Ruxton, 2002).

Rands et al. (2011b) considered a game theoretical framework to explore how the rules used by individuals with different dominance ranks could evolve, assuming these individuals paid attention to the ranks and energetic state of both themselves and the individual that they were interacting with. This model, and a companion simulation exploring the rules of thumb generated (Rands 2011a) demonstrated that both energetic state and social status are important for determining the behaviour of co-foraging individuals. Furthermore, individual-based simulations (Rands et al 2004, 2006) demonstrated that including an additional effect of dominance that led to subordinates having reduced access to food could lead not only to dominant individuals 
60 having higher energetic reserves than subordinates, but also subordinate individuals increasing

61 their activity.

62

63 We aimed to assess whether this framework was useful in understanding the foraging behaviour 64 of the horse. We were particularly interested to determine whether dominant animals had higher body condition and whether subordinate individuals showed increased activity in line with model

66

67

68

69 predictions. Horses are generalist herbivores with sophisticated social capacities. Free-ranging feral and primitive Przewalksi's horses spend a high proportion of each day foraging (52\%, Berger et al., 1999; 68\% Lamoot and Hoffman 2004; up to 75\% daylight and 53\% nocturnal, Mayes and Duncan, 1986)maintaining a high daily intake of plant material by grazing (or browsing) interrupted by frequent walking (Houpt, 2005). Accelerometry studies find similar proportions of time spent foraging by domestic horses kept on pasture (61\% daylight, 47\% nocturnal, Maisonpierre et al., 2019). Horses form strong affiliative bonds with familiar companions, but aggressive encounters and subtle threats, are also a common feature of equine social structure, particularly when resources are limited (Mills and Redgate, 2010). The current study was conducted under winter conditions where pasture availability was limited and a degree of competition for supplementary forage was evident. Thi situation applies commonly for domestic horses (kept for a variety of reasons including as companion animals or as conservation grazers (Gilhaus and Hoelzel, 2016) during winter periods within temperate zones). Understanding the factors that drive large inter-individual differences in body condition when group-living horses are kept during winter (e.g. Ingólfsdóttir and Sigurjónsdóttir, 2008; Giles et al., 2015; Yngvesson et al., 2019) is an important goal. It has been estimated that around a third of outdoor living horses and ponies within the UK are obese (Giles et al., 2014; Robin et al., 2015) but rates of obesity can reach 70\% in some populations (Menzies-Gow et al., 2017). It is timely to study the social factors influencing body condition in horses to reduce obesity prevalence and associated metabolic disease.

Previous empirical studies in horses have demonstrated that higher ranking individuals spend more time eating hay and have a higher body condition during the winter (Ingólfsdóttir and Sigurjónsdóttir, 2008; Giles et al., 2015) but have not examined the mechanisms behind this association. 
92 This study advanced our previous work by examining situations where bouts of foraging on 93 supplementary forage were interrupted for reasons including anti-predator vigilance and startle 94 responses (Goodwin, 1999), displacement interruptions directed towards or received from other 95 group members (Appleby, 1980; Rands et al., 2006) or short movements between foraging 96 locations (Duncan, 1980). We examined the duration, frequency and type of interruption to the 97 foraging behaviour of individual horses and ponies (hereafter termed "horses") living in social 98 herds. The total time attributed to interrupted foraging was considered as a proxy measure of 99 foraging efficiency (the ratio of energy gained over energy expended during foraging).

An important precursor to analysing foraging efficiency was understanding any differences in overall time spent foraging. We measured overall time spent foraging to check that individuals with a lower foraging efficiency didn't simply compensate by spending more time foraging. A unique feature of the study was the inclusion of measures of social status and body condition, enabling the assessment of associations not previously examined in foraging herbivores. Predictions suggest that subordinate individuals may suffer more displacement than dominant conspecifics (Goss-Custard et al., 1995; Stillman et al., 1997; 2000; Rands et al., 2006), reflected in increased displacement interactions and subsequent movement within foraging bouts. Dominant animals may also force subordinate conspecifics into more exposed foraging positions

110 (Ekman, 1987; Rands et al., 2004) leading to a reduction in foraging efficiency due to a greater 111 requirement for vigilance. In contrast, models predict that dominant individuals will be more 112 efficient foragers, feeding in positions with lower interference, potentially leading to a greater 113 energetic intake and overall body condition (Ekman, 1987; Schneider, 1984; Rands et al., 2006).

114 A greater body condition may in turn allow a subsequent competitive advantage (Rands, 2011;

115 Rands et al., 2006).

116

117 Our aims were to:

118 i) Confirm an association between dominance rank (adjusted for herd size, see

119 Methods) and body condition.

120 ii) Assess whether adjusted dominance rank is associated with interruptions to foraging (as a proxy for foraging efficiency). 
122 iii) Assess whether body condition is associated with interruptions to foraging (as a proxy 123 for foraging efficiency).

124 iv) Use multivariate analysis to investigate the contextual factors (age, breed, sex, height, supplementary feeding) that might influence these associations.

128

v) Consider the applied implications of our findings for the management of domestic horses.

\section{4 dominance to body condition.}

\section{Materials \& Methods}

140 The work was approved by the University of Bristol Animal Welfare and Ethical Review Board

141 (University Investigation Number UB/10/049) and all methods were carried out in accordance

142 with relevant guidelines.

143 The study sample was drawn from a population of outdoor, group-living horses based at

144 Redwings Horse Sanctuary (UK), that had been living together for at least three months and had 145 established social relationships. All of the individual animals were managed similarly, fed forage

146 from identical sources, lived in outdoor environments and were not ridden, meaning that

147 structured exercise could be removed as a potential confounding factor. Herds that included

148 pregnant or lactating mares were not considered for the study. Twenty study herds were selected 149 randomly from all remaining suitable herds within the sampling frame.

150 The policy of the sanctuary was to house horses in relatively compatible groups with shared 151 characteristics. Thus, larger horses were housed in separate herds from smaller ponies, all 
152 stallions were housed in one "bachelor" herd, while youngsters were also housed together, with

153 the few horses under 1 year of age (three individuals) accompanied by older "nanny" mares.

154 Herd size was 2-10 (mean $6 \pm 0.56$ individuals). 116 individuals ( 84 ponies of height $<148 \mathrm{~cm}$,

155 and 32 horses of height $\geq 148 \mathrm{~cm}$ ) from within these herds were observed between 2 December,

1562013 and 23 January, 2014. Ages ranged from 5 months to 32 years (11.83 \pm 0.63 years). Breeds

157 were native ponies (51.72\%), native cobs (17.24\%), lightweight horses (12.07\%), heavy horses

$158(5.17 \%)$, sports horse breeds (5.17\%) and other (8.62\%).

159

160 b) Study period and horse management

161 The winter months were chosen for observation as natural food resources were at their minimum

162 and therefore food based social interactions were likely at their highest due to the close

163 proximity of individuals. All horses lived in an outdoor paddock environment for 24 hours a day

164 and were fed from circular hay feeders provided at a fixed ratio of feeder space $(30 \mathrm{~cm})$ per

165 animal. Horses were fed twice daily with fresh hay replenished once at the start of morning

166 observation (between 08:00 and 09:00) and once at the start of afternoon observation (between

16711.30 and 13:00). Any uneaten hay remained in the hay feeder throughout the day. Twelve study

168 horses received additional supplementary feed from a bucket once a day, and this was recorded

169 as a potential confounder.

170

171 c) Time spent foraging

172 Each study herd was observed for six hours to assess overall time spent foraging, and

173 interruptions occurring during foraging bouts, once during a three hour morning session (08:00-

174 09:00 until 11:00-12:00) and once during a three hour afternoon session (11:30-13:00 until

175 14:30-16:00) on a different day within the same week, by a single trained observer. Due to the

176 time of year, these times were chosen based on daylight hours.

177

178 Time spent foraging was recorded using scan sampling at five minute intervals throughout each

179 three-hour observation period. A random number generator was used to determine the order in

180 which individuals were observed. Once this order was determined, all individuals were observed 
181 in sequence, in five-minute intervals. At each interval, it was recorded which individuals were

182 foraging and which were not. Foraging was defined as the horse ingesting either hay or grass,

183 with intermittent periods of the head down ingesting forage and the head up chewing this forage

184 material. The horse could be foraging from either the hay feeder or eating grass (although the

185 latter was rare as there was little grass available). The percentage of time spent foraging was then

186 calculated based on the number of intervals that each individual was foraging within the full six

187 hours of observation per herd.

188

189 Alongside this, continuous five minute focal animal observations were scheduled for each horse

190 during each three hour recording period. Each individual animal was independently observed for

191 at least 20 minutes $(4 \times 5$-minutes $)$ in total. These observations were predominantly used to

192 record foraging interruptions and social interactions (as detailed in sections $\mathrm{d}$ and e below),

193 however they were also used to more accurately estimate the total foraging time for each

194 individual. If an individual was not foraging for more than one minute during the five-minute

195 observation period, it was considered to have stopped foraging. The number of minutes it had

196 stopped foraging for were then subtracted from the total five minutes.

197

198 d) Foraging efficiency - duration and frequency of foraging interruptions

199 During the continuous five-minute focal animal observations, described above, observations

200 relating to foraging interruptions were also conducted. Interruption to foraging was defined as an

201 activity that was short in duration (less than one minute) and prevented the individual from

202 selecting, biting or chewing hay or grass. Both the frequency and overall duration of any

203 interruption was recorded and interruptions were categorised as one of the following:

204 Vigilance: Head raised from foraging and ears pricked in the direction of interest, the head is

205 higher and the ears upright distinguishing vigilance from raising the head to chew.

206 Movement whilst foraging: a short movement resulting in a change in foraging location, either

207 following a displacement by another individual or simply changing location at a walk.

208 Displacements given: interaction directed towards another individual, with the head outstretched

209 and ears flat back against the head resulting in recipient raising head, or taking a step away in

210 any direction. 
211 Displacements received: interaction received from another individual defined as above, causing

212 recipient to raise head, move sideways or take a step away in any direction.

213 Scratching: Using either the mouth or the hoof to scratch the body

214 Startle response: A quick reaction to an unexpected stimulus, the startle usually involved a quick

215 movement, either jump backwards or sideways followed by looking up with ears pricked

216

217 If any interruption lasted for over one minute then the individual was classed as having stopped

218 foraging. Note that individuals were only observed in detail when they were foraging, if an

219 individual was not foraging when it was due to be observed, this was recorded (to calculate total

220 foraging time, as described in section a) and but also counted as 'missed' in terms of recording

221 interruptions. Once a missed individual was foraging again it was observed next as a priority

222 (only if it had not yet already been observed for 20 minutes), but just for a single five-minute

223 interval, before resuming the original order. This was to maximise the collection of data on

224 foraging efficiency for each individual.

225

226 The frequency of foraging interruption (a proxy for foraging efficiency) was calculated as the

227 number of instances of all interruptions per minute foraging. Separate frequencies were also

228 determined for each interruption category (Table 1). The duration of interrupted foraging

229 referred to the total percentage of time spent interrupted per individual.

230

231

e) Dominance rank

232

233 Although the concept of dominance lacks universal explanatory power in describing social

234 structure, it is a useful construct when considering the specific context of competition for a

235 limited food resource. Under such conditions, horses generally follow a linear ranking hierarchy,

236 with occasional triangles and some influence of third-party interactions (Houpt et al., 1978; van

237 Dierendonck et al., 1995; Hartmann et al., 2017).

238

239 Here we defined dominance "an asymmetry in the outcome of dyadic interactions between

240 individuals, or a priority of access to resources" (Drews, 1993) and assessed it by measuring 
241 outcomes between dyadic pairs when feeding from hay feeders. Agonistic interactions were

242 recorded continuously throughout the three-hour observation period (these were easily

243 measurable alongside other observations). An agonistic interaction was defined as one individual

244 approaching or displaying to another with the neck outstretched and ears back flat against the

245 head and, crucially, the second individual moving away. Dominance rank was then calculated

246 using the methods described by Appleby (1980). The number of agonistic interactions both

247 given and received was recorded for each herd individual, and then the number of other

248 individuals that a focal individual both dominated and was dominated by was calculated.

249

250 Once an Appleby rank had been given, this was then adjusted to take into account herd size (as

251 in Giles et al., 2015). Adjusted dominance rank was calculated as $1-(a-1) /(h-1)$, where $a$ is

252 the Appleby rank and $h$ is the herd size. Where dominance rank or dominance status is referred

253 to in this manuscript, this refers to this adjusted dominance rank.

255

256

257

258

259

260

261

262

263

264

265

266

267

268

269

\section{f) Body condition score}

Measurements were taken immediately after the second set of observations on the herd had been completed. All study animals were accustomed to being handled. Body condition score was measured using the Henneke nine-point scale (Henneke et al., 1983) by a single trained observer (SLG). Six areas of the horse were scored between 1 and 9 and then averaged and rounded to the nearest 0.5 , to obtain a single score. A score of five on the scale was taken to indicate an ideal body condition.

(1)

\section{g) Statistical analyses}

Results were analysed using Stata 12.1 (Statacorp, Texas). Univariable relationships were assessed using mixed effects linear regression, the clustered study design was controlled for by including herd group and herd size as a random effects, on the basis that herd size or other herd specific factors such as environment could plausibly have some influence on foraging and interactive behaviours. Univariable relationships of primary interest were: 
1) The relationship between dominance rank (adjusted for herd size) and body condition score

2) The relationship between dominance rank (adjusted for herd size) and interruptions to foraging (as a proxy for foraging efficiency)

3) The relationship between body condition and interruptions to foraging (as a proxy for foraging efficiency)

Following an initial univariable exploration of these relationships, relationships between the separate foraging interruption variables were also considered. In addition, breed, age, height, sex and whether or not the individual received supplementary feed were recorded as potential confounding variables. To be considered a potential confounder the variable had to be associated with both the explanatory and outcome variable, and not on the causal pathway between the two (Petrie and Sabin, 2009). Statistical significance was defined using $p \leq 0.05$ with a screening $p$ value for multivariable models of $p \leq 0.07$.

Mixed effects multivariable linear regression was then used to build a best-fit explanatory model 286 for both adjusted dominance rank and body condition. The foraging interruption variables (see Table 1 for list) were added to the model one at a time, based on the strength of univariable association, starting with a minimal model. A likelihood ratio test was used to assess the contribution of each variable to the model fit and variables were retained on the basis of this and the adjusted $p$ value.

Multivariable analysis using a mixed effects linear regression model was also used to make predictions regarding interruptions to foraging - to explore whether this could be a possible mechanism linking dominance status and body condition. Duration of foraging interruption was associated with both dominance status and body condition, therefore this was added to a model containing adjusted dominance rank and body condition. Its explanatory contribution to the model was then assessed using both the adjusted $p$ and estimates and a likelihood ratio test. 298

\section{Results}


300 During $120 \mathrm{~h}$ of observation, the amount of time that individual animals spent foraging averaged

$30176.4 \%$ SD 0.17. Values per herd are given in Table S1. Figure 1 shows that there was no

302 significant correlation between adjusted dominance rank and total foraging time $\left(r^{2}=0.004, n=\right.$

$303116, p=0.51)$ and Figure 2 shows that there was no significant correlation between body

304 condition score (range 4 to 8.5$)$ and total foraging time $\left(r^{2}=0.016 ; n=116, p=0.182\right)$. This is

305 important in the interpretation of subsequent results.

306

307 a) Univariable Analysis

308

309

The relationship between adjusted dominance rank and body condition score

310

Adjusted dominance rank was positively associated with body condition score within our study

311 population (Table 1).

312

313 Foraging Efficiency

314 During approximately $92 \mathrm{~h}$ of the $120 \mathrm{~h}$ total observation period, horses were foraging (total

315 across all horses). During this time, the observed total numbers of each type of interruption

316 contributing to foraging efficiency were: vigilance 2518; movement whilst foraging 454;

317 displacements given 198; displacements received 222; scratching 65; startle responses 5.

318

319 The relationship between dominance rank and foraging efficiency

320 Although the frequency of foraging interruptions did not show evidence of association with

321 adjusted dominance $\operatorname{rank}(Z=-1.55, p=0.12$, Table $\mathrm{S} 2)$, the total duration of interruptions

322 decreased as adjusted dominance rank increased (Table 1). An increase in adjusted dominance

323 rank was also associated with a decrease in some specific interruption behaviours, namely

324 instances of movement whilst foraging, displacements given, and displacements received (Table

325 1). Figure 1 shows that the reduced foraging efficiency of subordinate individuals is not

326 compensated for by an increase in total foraging time.

328 The relationship between body condition score and foraging efficiency

329 The number of incidences (frequency) of foraging interruptions occurring during foraging bouts

330 was lower for animals with higher body condition scores. Vigilance decreased with an increase 
331 in body condition (Table 1), but none of the other separately defined foraging interruptions

332 showed any association with body condition (Supplementary Information, Table S2). Figure 1

333 shows that the reduced foraging efficiency of individuals with lower body condition is not

334 compensated for by an increase in total foraging time.

335

336

337

Associations between the individual foraging interruption variables and consideration of

338 potential confounders

Frequency of 'displacements received' was strongly associated with 'moving whilst foraging'

339

and 'displacements given'. Frequency of 'displacements given' was also associated with

340

'moving whilst foraging' (Table 1).

341

In this study, none of the potential confounder variables (breed, age, height, sex) were associated

342 with body condition score, adjusted dominance rank or any category of interrupted foraging, and

343 there were no biologically plausible interactions, therefore adjusted estimates were not required.

344 This also included whether or not a horse received additional supplementary feed, which showed

345 no evidence of association with either adjusted dominance rank $(Z=-0.50, p=0.61)$ or body

346 condition $\left(X_{9}^{2}=12.40, p=0.19\right)$.

347 b) Multivariable analysis

348 Model for adjusted dominance rank

349 Controlling for other model variables, frequency of 'displacements received', 'displacements

350 given' and body condition score were associated with adjusted dominance rank (Table 2).

351 Model for body condition score

352 Controlling for other model variables, vigilance frequency and adjusted dominance rank were

353 strongly associated with body condition score (Table 3 ).

354

355

356

The relationship between body condition score and adjusted dominance rank when taking into account interruptions to foraging

The association between body condition score and adjusted dominance rank was weaker when

359 total duration of foraging interruptions (or time spent interrupted) was included in the model

360 (Table $4, p=0.06$, as opposed to $p=0.03$ in the univariable model). The effect size also reduced 
361 slightly (from a 0.66 increase in adjusted dominance rank per half unit of body condition score to

362 0.55). The likelihood ratio test results (Table 4) indicate that duration of foraging interruptions

363 has a more significant contribution to the model fit $(p=0.04)$ than adjusted dominance rank $(p=$ 364 0.06).

365

366

\section{Discussion}

367

368

The study explored the inter-relationships between foraging interruptions, dominance and body condition, controlling for herd size and herd identity effects. No effects of age, sex or height were detected in our study. Clearly, large horses have differing energy requirements from smaller ponies, whilst growing youngsters and older horses with reduced digestive efficiency (e..g Ralston et al., 1989) will also differ from young but mature adults. However, the horses in our study were housed in herds that contained animals of similar characteristics (see Methods and Supplementary Table). For example, heavy horses were housed separately from lighter Thoroughbreds and smaller ponies. Although this policy greatly reduces or eliminates our ability to detect age and sex effects on foraging, it enhances our ability to detect the relative effects of dominance and body condition within herds. Importantly, our analysis showed that the relationships we detected applied across all herd types.

Within this study population, dominance status was positively associated with body condition, although this relationship was weaker when foraging efficiency was included in the multivariate model (Table 4). In addition, the association between body condition and foraging efficiency was stronger than that between body condition and dominance. Thus, whilst dominance explains some variation in body condition, our results highlight the potential role of factors other than social dominance that could influence foraging efficiency. Factors such as a tendency to show vigilance behaviour have been little explored to date but have the potential to greatly influence the ratio of energy gained vs energy expended during bouts of foraging.

There was no evidence that subordinate or low body condition individuals compensated for less efficient foraging by increasing total foraging time. Another recent study found that horses with low body condition tend to adopt more passive behaviour (Jorgensen et al., 2016). Potentially 
392 such results may be due to a strong motivation to feed as a group in this species and thus

393 synchronise feeding and resting behaviour (Rands et al., 2008). Subordinate or lower body score

394 individuals were unlikely to remain foraging when conspecifics were not, supporting suggestions

395 that social factors may result in stable differences in body condition within group living animals

396 (Rands, 2011; Rands et al., 2010). Indeed the tendency to synchronous feeding and resting (as in

397 sheep, McDougall and Ruckstuhl, 2018) may be hard-wired as an adaptivebehaviour.

398 The lack of a compensatory change in total foraging time means that any variation observed in

399 foraging efficiency could plausibly have an effect on body condition.

400

401 Given these results and previous theoretical predictions, an association between foraging

402 efficiency, dominance and overall body condition was expected (McNamara and Houston, 1990;

403 Stillman et al., 2000; Rands et al., 2006; Rands and Whitney, 2008) but our study is the first to

404 explore the role of the different components of foraging efficiency, such as movement, social

405 displacement or vigilance.

406

407

Vigilance and body condition

408

409 Vigilance frequency was the individual interruption behaviour most strongly associated with

410 body condition score - it showed a strong negative association. However, vigilance was not

411 associated with dominance status. These results suggest that certain individuals may be more

412 likely to conduct vigilance, perhaps on behalf of the group, regardless of their social status.

413 These results do seem to support the suggestion that vigilance is an inherently costly activity

414 (Elgar, 1989; Fritz et al., 2002; Fattorini and Ferretti, 2019; Pacheco and Herrera, 1999) as

415 demonstrated by the negative association with body condition. However, lower body condition

416 individuals may also be more stressed or nervous individuals, which would also explain the

417 association with increased vigilance.

418

419 The complexity of vigilance as a single trait may somewhat explain the lack of observed

420 association with dominance status. Vigilance may serve a range of functions in group living

421 animals (Fattorini and Ferretti, 2019), including anti-predatory behaviour (Elgar, 1989; Hunter

422 and Skinner, 1998), monitoring of other herd members and scanning the environment for 
423 resources (Underwood, 1982). Ungulate mammals that are unexposed to predation have been

424 observed to greatly reduce their vigilance behaviour (Hunter and Skinner, 1998). Horses,

425 unexposed to predation, may therefore show relatively low levels of vigilance, with reasons other

426 than anti-predatory vigilance having a proportionally larger role.

427

428 Alongside the association between dominance status and body condition, the association between

429 body condition and vigilance provides evidence of two separate behavioural traits associated

430 with body condition in group living animals. Behavioural predictors of body condition have so

431 far received little attention in horses (for exceptions, see Ingólfsdóttir and Sigurjónsdóttir, 2008;

432 Giles et al., 2015) and may warrant continued investigation, especially as obese horses (BCS >7)

433 may show differences in activity and eating behaviour when compared to lean horses (BCS 4-5)

434 (Moore et al., 2019).

435

436

\section{Dominance status, movement during foraging and displacement interactions}

437

438 Subordinate horses showed more movement whilst foraging, and were (as expected) more likely

439 to receive displacements. Indeed, statistical analysis revealed that displacement was strongly

440 associated with movement during foraging in our study population, with subordinate animals

441 forced to move foraging location. Theoretical models and empirical studies have proposed that

442 subordinate individuals may be forced to foraging positions carrying a greater risk of predation

443 (Hamilton, 1971; Hemelrijk, 2000). Future studies could examine whether subordinate animals

444 showed increased vigilance specifically when in displaced locations, and during non-foraging

445 periods.

446

447 Overall our results therefore appear to support predictions that displacement reduces foraging

448 efficiency for the recipient (Bautista et al., 1998; Stillman et al., 2002). Valuable foraging time is

449 wasted not only over the initial dispute, but also in relocating to a new foraging location. In

450 contrast, dominant horses tended to interrupt their own foraging to displace others, but these

451 interruptions tended to be of short duration, allowing the dominant animal to return quickly to

452 foraging. As our study herds were feeding from hay feeders, potentially displacement and 
453 movement occurred more often than would occur during foraging on pasture, due to the

454 artificially close proximity of herd members (Hoffman et al., 2009).

455

456

\section{Conclusions}

457

These results are novel and exciting in that they present the first behavioural evidence

458 confirming a broad body of influential theoretical work (e.g. Marshall et al., 2012; Petit and Bon, 459 2010; Rands et al., 2003; 2006; Rands 2011; Sueur et al., 2013) linking condition and behaviour in a group-living species. Our results suggest (in line with model predictions) that differences in energetic reserves (body condition) can emerge simply via a reduction in energetic intake by subordinates when dominants are present. This hypothesis could be further tested in a future prospective study. One application of our work is that information on individual horse dominance status could be included as a relevant factor when addressing health problems associated with equine obesity (Giles et al., 2014; Robin et al., 2015; Menzies-Gow et al., 2017).

\section{Acknowledgements}

We thank the staff at Redwings Horse Sanctuary, especially Roxane Kirton and Anne Whitehorn for their kind help with conducting the dominance tests and for the use of their horses and ponies.

\section{References}

Appleby, MC 1980. Social rank and food access in red deer stags. Behaviour 74: 294-309.

481 Clark, CW, Ekman, J 1995. Dominant and subordinate fattening strategies: a dynamic 
483 Drews, C 1993. The concept and definition of dominance in animal behaviour. Behaviour 484 125: $283-313$

485 Duncan, P 1980. Time-budgets of Camargue horses II. Time-budgets of adult horses and 486 weaned sub-adults. Behaviour 72: 26-48.

487 Ekman, J 1987. Exposure and time use in willow tit flocks: the cost of subordination. Animal $488 \quad$ Behaviour 35: 445-452

489 Elgar, MA 1989. Predator vigilance and group size in mammals and birds: a critical review 490 of the empirical evidence. Biological Reviews 64: 13-33

491 Fattorini, N, Ferretti, F 2019. To scan or not to scan? Occurrence of the group-size effect in 492 a seasonally nongregarious forager. Ethology 125: 263-275

493 Fritz, H, Guillemain, M, Durant, D 2002. The cost of vigilance for intake rate in the mallard 494 (Anas platyrhynchos): an approach through foraging experiments. Ethology Ecology and $495 \quad$ Evolution 14, 91-97.

496 Gilhaus, K, Hoelzel, N 2016. Seasonal variations of fodder quality and availability as constraints for stocking rates in year-round grazing schemes. Agriculture, Ecosystems and Environment 234 (S1) 5-15.

500 factors in outdoor living domestic horses and ponies. PeerJ 2: e299 (2014).

501 Giles, SL, Nicol, CJ, Harris, PA, Rands, SA 2015. Dominance rank is associated with body 502 condition in outdoor-living domestic horses (Equus caballus). Applied Animal Behaviour

$503 \quad$ Science 166: 71-79

504 Goodwin, D 1999. The importance of ethology in understanding the behaviour of the horse.

505 Equine Veterinary Journal 31(S28): 15-19

506 Goss-Custard, JD, Caldow, RWG, Clarke, RT, West, AD 1995. Deriving population

507 parameters from individual variations in foraging behaviour. II. Model tests and population

508 parameters. Journal of Animal Ecology. 64, 277-289.

509 Hamilton, WD 1971. Geometry for the selfish herd. Journal of Theoretical Biology 31: 295$510 \quad 311$

511 Hartmann E, Christensen JW, McGreevy PD 2017. Dominance and leadership: useful 512 concepts in human-horse interactions? Journal of Equine Veterinary Science 52: 1-9 
513 Hemelrijk, CK 2000. Towards the integration of social dominance and spatial structure.

514 Animal Behaviour 59: 1035-1048

515 Hemelrijk, CK 2002. Understanding social behaviour with the help of complexity science.

516 Ethology 108: 655-671

517 Henneke, DR, Potter, GD, Kreider, JL, Yeates, BF 1983. Relationship between condition

518 score, physical measurements and body fat percentage in mares. Equine Veterinary Journal,

519 15: $371-372$

520 Hoffmann, G, Bockisch, F-J, Kreimeier, P 2009. Einfluss des Haltungssystems auf die

521 Bewegungsaktivität und Stressbelastung bei Pferden in Auslaufhaltungssystemen.

522 Landbauforsch. Völk. 2: 105-112

523 Houpt, KA 2005. Maintenance behaviours. In: Domestic Horse: The Origins, Development

524 and Management of its Behaviour, Edited by: Mills, DS, McDonnell, SM, pp 94-109.

525 Houpt KA, Law K, Martinisi V 1978. Dominance hierarchies in domestic horses. Applied

526 Animal Ethology 4: 273-283

527 Houston, AI, McNamara, JM 1999. Models of Adaptive Behaviour: an Approach Based on

528 State. Cambridge: Cambridge University Press.

529 Hunter, LTB, Skinner, J D 1998. Vigilance behaviour in African ungulates: the role of

530 predation pressure. Behaviour 135: 195-211

531 Ingólfsdóttir, H B, Sigurjónsdóttir, H 2008. The benefits of high rank in the wintertime - a

532 study of the Icelandic horse. Applied Animal Behaviour Science 114: 485-491

533 Jorgensen, GHM, Aaensen, L, Mejdell, CM, Boe, KE 2016. Preference for shelter and

534 additional heat in horses exposed to Nordic winter conditions. Equine Veterinary Journal 48:

$535720-726$.

536 Krause, J, Ruxton, G D 2002. Living in groups. Oxford: Oxford University Press.

537 Lamoot, I, Hoffmann, M 2004. Do season and habitat influence the behaviour of Haflinger

538 mares ina coastal dune area? Belgian Journal of Zoology 134: 97-103.

539 Maisonpierre, IN, Sutton, MA, Harris, P, Menzies-Gow, N, Weller, R, Pfau, T 2019.

540 Accelerometer activity tracking in horses and the effect of pasture management on time

541 budget. Equine Veterinary Journal 51: 840-845 
542 McDougall, PL, Ruckstuhl, KE 2018. Doing what your neighbour does: neighbour

543 proximity, familiarity and postural alignment increase behavioural mimicry. Animal

544 Behaviour 135: 177-185.

545 McNamara, JM, Houston, AI 1990. The value of fat reserves and the tradeoff between

546 starvation and predation. Acta Biotheoretica 38: 37-61

547 Marshal, HH, Carter AJ, Rowcliffe JM \& Cowlishaw G. 2012. Linking social foraging

548 behaviour with individual time budgets and emergent group-level phenomena. Animal

549 Behaviour 84: 1295-1305.

550 Mayes, E, Duncan, P 1986. Temporal patterns of feeding in free-ranging horses. Behavior

$55196: 105-129$.

552 Menzies-Gow, NJ, Harris, PA, Elliott, J 2017. Prospective cohort study evaluating risk

553 factors for the development of pasture-associated laminitis in the United Kingdom. Equine

554 Veterinary Journal 49: 300-306

555 Mills, D, Redgate, S 2017. Behaviour of horses. In “The Ethology of Domestic Animals" $3^{\text {rd }}$

556 Edition. Edited by Per Jensen, CAB International.

557 Moore, JL, Siciliano, PD, Pratt-Phillips, SE 2019. Voluntary energy intake and expenditure

558 in obese and lean horses consuming ad libitum forage. Journal of Equine Veterinary Science.

$559 \quad \mathbf{7 4}, 13-20$.

560 Pacheco, MA, Herrera, EA 1999 Social structure of feral horses in the Llanos of Venezuela.

561 Journal of Mammalogy 78: 15-22.

562 Petit, O, Bon R. 2010. Decision-making processes: the case of collective movements.

563 Behavioural Processes 84: 635-647.

564 Petrie, A, Sabin, C 2009 Medical Statistics at a Glance (third edition). Chichester: Wiley.

565 Ralston, SL, Squires,EL, Nockels, CF 1989 Digestion in the aged horse. Journal of Equine

566 Veterinary Science 8: 203-205.

567 Rands, SA 2011a. Approximating optimal behavioural strategies down to rules-of-thumb:

568 energy reserve changes in pairs of social foragers. PLoS One 6: e22104

569 Rands, SA 2011b. The effects of dominance on leadership and energetic gain: a dynamic

570 game between pairs of social foragers. PLoS Computational Biology 7: e1002252

571 Rands, SA, Cowlishaw, G, Pettifor, RA, Rowcliffe, JM, Johnstone, RA 2003. The

572 spontaneous emergence of leaders and followers in a foraging pair. Nature 423: 432-434 

rules for social animals in selfish herds. Proceedings of the Royal Society, Section B 271:

$575 \quad 2613-2620$

576 Rands, SA, Pettifor, RA, Rowcliffe, JM, Cowlishaw, G 2006. Social foraging and dominance relationships: the effects of socially mediated interference. Behavioural Ecology and Sociobiology 60: 572-581 emergence of leaders and followers in foraging pairs when the qualities of individuals differ. BMC Evolutionary Biology 8: 51

582 Rands, SA, Whitney, HM 2008. Floral temperature and optimal foraging: is heat a feasible floral reward for pollinators? PLoS One 3: e2007 Prevalence of and risk factors for equine obesity in Great Britain based on owner-reported body condition scores. Equine Veterinary Journal. 47: 196-201

Schneider, K J 1984. Dominance, predation, and optimal foraging in white-throated sparrow flocks. Ecology 65: 1820-1827

Stillman, RA, Goss-Custard, JD, Caldow, RWG 1997. Modelling interference from basic foraging behaviour. Journal of Animal Ecology 66: 692-703 in intake rate: the relative importance of foraging efficiency and dominance. Journal of Animal Ecology 69: 484-493 interference in common cranes. Journal of Animal Ecology. 71: 874-882 Sueur C, MacIntosh AJJ, Jacobs AT, Watanabe K, Petit O. 2013. Predicting leadership using nutrient requirements and dominance rank of group members. Behavioral Ecology and Sociobiology 67: 457-470.

Underwood, R 1982. Vigilance behaviour in grazing African antelopes. Behaviour 79: 81107

van Dierendonck MC, de Vries H, Schilder MBH 1995. An analysis of dominance, its behavioural parameters and possible determinants in a herd of Icelandic horses in captivity. Netherlands Journal of Zoology 45: 362-385 
604 Yngvesson, J., Torres, JCR, Lindholm, J, Pattiniemi, A, Andersson, P, Sassner, H. 2019.

605 Health and body conditions of riding school horses housed in groups of kept in conventional

606 tie-stall/box housing. Animals 9: article 73.

607 


\section{Table $\mathbf{1}$ (on next page)}

Statistically significant univariable associations $(p \leq 0.05)$ using mixed effects linear regression, controlling for herd group and herd size as a random effects. 
1 Table 1. Statistically significant univariable associations $(p \leq 0.05)$ using mixed effects linear regression, controlling for herd group

2 and herd size as a random effects. Non-significant associations are given in the supplementary material, Table S2.

3

Interruption behaviour variables

B S.E.

$95 \% \mathrm{CI}$

0.66

0.29

$0.09-1.24$

2.27

0.023

Condition Score

Body condition and foraging efficiency

Frequency

Total instances of interruptions

$-0.77$

0.29

$-1.33--0.21$

$-2.71$

0.007

Instances of vigilance

$-0.93$

0.30

$-1.52--0.34$

$-3.09$

0.002

Duration

Total duration of interruptions

0.08

0.04

$-0.15--0.01$

2.50

0.012

Adjusted dominance rank and foraging

efficiency

Frequency

Instances of moving whilst foraging

Instances of displacements received

Instances of displacements given
$-0.07$

1.36
0.30

$-1.45--0.25$

$-2.77$

0.006

0.02

$-0.11--0.03$

$-3.62$

$<0.001$
0.33

$0.71-2.01$

$4.12<0.001$ 
Total duration of interruptions

$-0.02$

0.0

$-0.04--0.001$

$-2.06$

0.039

Associations between interruption

behaviour variables

Frequency of displacements received

Instances of moving whilst foraging

Instances of displacements given

Frequency of displacements given

$\begin{array}{lllll}0.20 & 0.06 & 0.08-0.32 & 3.38 & 0.001 \\ -0.16 & 0.07 & -0.29--0.02 & -2.30 & 0.021\end{array}$

Instances of moving whilst foraging
$-0.16$

0.08
$-1.90$

0.057 


\section{Table 2 (on next page)}

The final multivariable explanatory model for adjusted dominance rank, using mixed effects linear regression, controlling for herd group and herd size as random effects. 
1 Table 2. The final multivariable explanatory model for adjusted dominance rank, using mixed

2 effects linear regression, controlling for herd group and herd size as random effects.

3

\begin{tabular}{lccccc}
\hline Explanatory variable & $\boldsymbol{\beta}$ & $\mathbf{S E}$ & $\mathbf{9 5 \%}$ CI & $\boldsymbol{Z}$ & $\boldsymbol{p}$ \\
\hline Frequency of being displaced & -2.71 & 0.35 & $-3.43--2.00$ & -7.43 & $<0.001$ \\
Frequency of displacement towards others & 0.86 & 0.28 & $0.31-1.40$ & 3.11 & 0.002 \\
Body condition score & 0.04 & 0.02 & $0.005-0.08$ & 2.20 & 0.027 \\
Constant & 0.26 & 0.13 & $0.01-0.52$ & 2.06 & 0.039 \\
\end{tabular}

4

5 


\section{Table 3 (on next page)}

The final multivariable explanatory model for body condition score, using mixed effects linear regression, controlling for herd group and herd size as random effects. 
1 Table 3. The final multivariable explanatory model for body condition score, using mixed

2 effects linear regression, controlling for herd group and herd size as random effects.

3

\begin{tabular}{lccccc}
\hline Explanatory variable & $\boldsymbol{\beta}$ & $\mathbf{S E}$ & $\mathbf{9 5 \%} \mathbf{C I}$ & $\boldsymbol{Z}$ & $\boldsymbol{p}$ \\
\hline Vigilance frequency & -0.89 & 0.30 & $-1.48--0.31$ & -3.01 & 0.003 \\
Adjusted dominance rank & 0.63 & 0.29 & $0.06-1.18$ & 2.19 & 0.029 \\
Constant & 6.14 & 0.23 & $5.68-6.59$ & 26.55 & $<0.001$
\end{tabular}

4

5

6

7 


\section{Table 4 (on next page)}

Multivariable linear regression model showing the effect of foraging efficiency (total duration of foraging interruptions) upon the relationship between dominance status and body condition. 
1 Table 4. Multivariable linear regression model showing the effect of foraging efficiency (total duration of foraging interruptions) upon

2 the relationship between dominance status and body condition.

3

\begin{tabular}{|c|c|c|c|c|c|c|c|}
\hline \multirow[b]{2}{*}{ Explanatory variable } & \multirow[b]{2}{*}{$\beta$} & \multirow[b]{2}{*}{$\mathbf{S E}$} & \multirow[b]{2}{*}{$95 \% \mathrm{CI}$} & \multirow[b]{2}{*}{$\mathbf{Z}$} & \multirow[b]{2}{*}{$p$} & \multicolumn{2}{|c|}{ Likelihood Ratio Test } \\
\hline & & & & & & $\chi^{2}{ }_{1}$ & $p$ \\
\hline Adjusted dominance rank & 0.55 & 0.29 & $-0.03-1.13$ & 1.86 & 0.06 & 3.39 & 0.06 \\
\hline $\begin{array}{l}\text { Total duration of foraging } \\
\text { interruptions }\end{array}$ & -0.07 & 0.04 & $-0.15--0.005$ & -2.12 & 0.03 & 4.29 & 0.04 \\
\hline Constant & 6.10 & 0.28 & $5.55-6.64$ & 22.12 & $<0.001$ & - & - \\
\hline
\end{tabular}

4

5

6 
Figure 1

Total foraging time as a function of adjusted dominance rank

Foraging time was observed for the 116 study horses and expressed as a proportion of each individual's total time budget. Horses were kept in 20 discrete herds, and dominance rank was adjusted for herd group size. The plot shows a lack of association between dominance rank and total foraging time.

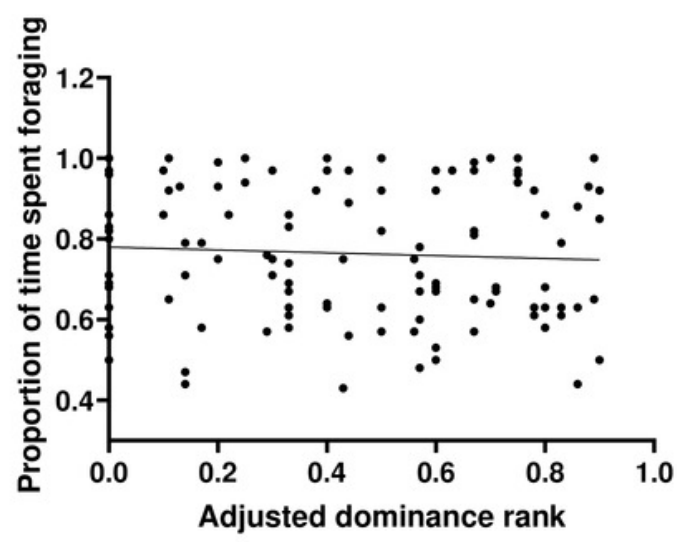


Figure 2

Total foraging time as a function of body condition score

Foraging time was observed for the 116 study horses and expressed as a proportion of each individual's total time budget. Body condition score was assessed using the Henneke 9-point scale. The plot shows a lack of association between body condition score and total foraging time.

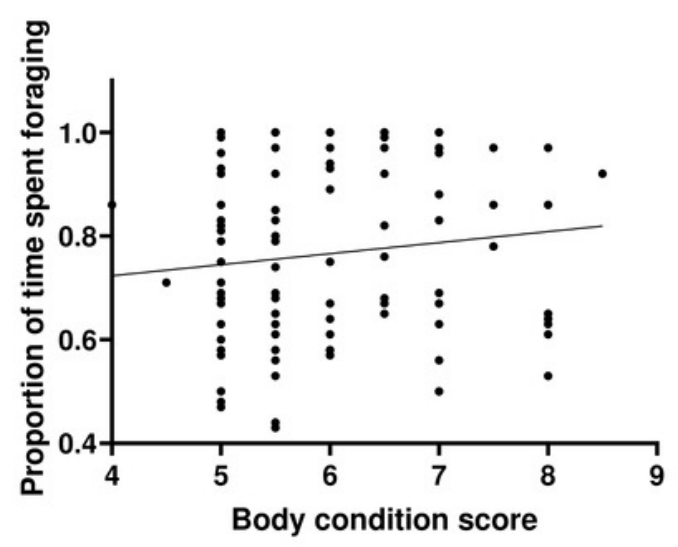

